\title{
Being Admired or Being Liked: Classroom Social Status and Depressive Problems in Early Adolescent Girls and Boys
}

\author{
Albertine J. Oldehinkel • Judith G. M. Rosmalen • \\ René Veenstra · Jan Kornelis Dijkstra · Johan Ormel
}

Published online: 31 January 2007

(C) Springer Science+Business Media, LLC 2007

\begin{abstract}
This study investigates associations between depressive problems and classroom social status in a large population cohort of Dutch early adolescents $(N=1046$, age $13.52 \pm 0.51,52.4 \%$ girls). Depressive problems were assessed by parent and self-reports and classroom status by peer nominations. We assessed peer status with respect to both achievement-related (being a good learner, being good at sports, being good-looking) and affection-related (being liked, being disliked, being best friend) areas. In boys, depressive problems were most strongly associated with not being good at sports, while in girls the association was strongest for not being liked. The risk of a low status in one area could largely be compensated by a high status in another area.
\end{abstract}

Keywords Depressive symptoms · Social hierarchy · Adolescent $\cdot$ Gender

Depressive problems and low social status have been associated since ancient times. In fact, the word depression is

A. J. Oldehinkel $(\bowtie) \cdot$ J. G. M. Rosmalen · J. Ormel Department of Psychiatry and Graduate School of Behavioral and Cognitive Neurosciences, University Medical Center Groningen, University of Groningen, P.O. Box 30.001, 9700 RB Groningen, The Netherlands

e-mail: a.j.oldehinkel@med.umcg.nl

\section{A. J. Oldehinkel}

Department of Child and Adolescent Psychiatry, Erasmus University Medical Center - Sophia Children's Hospital Rotterdam, The Netherlands

R. Veenstra · J. K. Dijkstra

Department of Sociology and Interuniversity Center for Social Science Theory and Methodology (ICS), University of Groningen, The Netherlands derived from the Latin term deprimere, which means being brought down in status or fortune (Jackson, 1986). The association between depression and social status has been confirmed empirically in numerous studies, in both animals and humans (e.g., Blanchard \& Blanchard, 1990; Eaton \& Harrison, 2000; Gilbert, Allan, \& Trent, 1995; Hecht, Inderbitzen, \& Bukowski, 1998).

Social status can be defined in at least two ways: in terms of achievements (being admired) and in terms of affection (being liked). These two definitions are related, but by no means interchangeable, and could be differentially linked to depressive problems. The former contains an element of competition (being better than others), while the latter relates to being accepted or rejected by the social group. We will compare the relative importance of both of them with respect to depressive problems in early adolescent girls and boys.

Adolescence is a developmental context in which peer status is particularly salient (Connell \& Dishion, 2006). Adolescents spend considerably more time in peer interactions than younger children (Larson \& Richards, 1991), and use peers as primary sources for social comparison and selfappraisal (Prinstein \& Aikins, 2004). Adolescence is also a highly interesting developmental stage for studying depressive problems, because the prevalence of these problems increases substantially in this phase of life, especially in girls (e.g., Hankin et al., 1998; Oldehinkel, Wittchen, \& Schuster, 1999).

Achievement- and affection-related social status

Achievement-related operationalizations of social status are usually based on Price's Social Ranking Theory (Gilbert \& Allan, 1998; Price, 1972). Briefly, this theory postulates that in pursuing scarce resources (e.g., territories, sexual opportunities), animals will have to fight others aiming at the same 
resources. To prevent harm, animals who are likely to lose these conflicts need inhibitory mechanisms that force them to submit (withdraw, run away) and downgrade their aspirations so that they do not keep engaging in fights they cannot win. These inhibitory strategies may result in behavioral and physiological phenomena that closely resemble depressive symptoms in humans (e.g., Blanchard \& Blanchard, 1990; Sapolsky, 1990). Hence, according to this theory, depression is an involuntary strategy to accept defeat in (ritual) agonistic encounters and to accommodate what would otherwise be unacceptably low social rank (Price, Sloman, Gardiner, Gilbert, \& Rohde, 1994).

Human social hierarchy does not need actual (ritual) fighting to be established, but can also be formed by imagining what would happen in case of such an encounter. Just knowing the strength of your opponent may be enough to experience a sense of inferiority (Rohde, 2001), which in turn can boost depressive problems (Brown, Harris, \& Hepworth, 1995; Gilbert \& Allan, 1998). Internal hierarchical positions are also fed by the amount of social attention directed by others (Gilbert, 1989). As opposed to most other species, humans base (internal) hierarchies not just on physical strength, but on other capacities related to the availability of resources, such as intelligence and physical attractiveness (e.g., Anderson, John, Keltner, \& Kring, 2001; Nettle, 2003), as well.

Whereas Price's Social Ranking Theory is achievementoriented and implies (possibly internal) social comparison and grading, peer status can also be defined in terms of affection, that is, being liked or disliked (rejected). While achievement-related status mainly refers to the hierarchical position within the group, affection-related status may also have implications for group membership in itself. Throughout human history, being banished from the group has been similar to a death sentence, so it is not surprising that being accepted by other people represents a core motive (e.g., Baumeister \& Leary, 1995; Fiske, 2004). Hence, social rejection is a significant stressor (Coie, 1990), which can bring about feelings of loneliness (Asher \& Wheeler, 1985) and low self-esteem (O'Brien \& Bierman, 1988), and may contribute to the development of depressive problems (Boivin, Poulin, \& Vitaro, 1994; Monroe \& Hadjiyannakis, 2002).

Social ranking and social rejection theories offer sound theoretical frameworks to predict depressive problems in those with a low status, but are less explicit regarding consequences of having a high status. Although there is a social gradient of (mental) ill-health, that is, health improves with each step one moves up the socioeconomic ladder (e.g., Siegrist \& Marmot, 2004), this may not be translated directly to the association between peer status and depressive problems in adolescence. In fact, animal research suggest that both high- and low-status individuals can suffer from distress, among other things depending on their personality and the stability of the hierarchy (Sapolsky, 2005). Hence, high and low peer status may not be two sides of the same coin, and better be investigated separately.

Though adolescents' social status is multidimensional (Rohde, 2001), the achievement-related and the affectionrelated approaches to social status have evolved independently from each other and have, to the best of our knowledge, never been studied in concert. Hence, it is not known how the two are interrelated and how they jointly affect depressive problems. Multiple hierarchies exist within each of the two status domains as well: achievement includes specific areas such as sports and school performance; and affection may relate to being disliked or being someone's best friend. This raises the question if and how a low status in one of the areas can be compensated by a high status in another area, or vice versa. Being caught in a (degrading) situation where no escape seems possible is a particularly potent trigger of depressive problems (Brown et al., 1995). A position at the bottom of the status hierarchy may be experienced as such, but this is considerably less likely in adolescents who are highly regarded in other respects, since people tend to value most the hierarchy in which they rank highest (Sapolsky, 2005). We therefore expected that the effects of low status could be compensated by high status in another area.

\section{Gender differences}

Until now, only a limited number of studies have focused on gender differences in associations between social status in particular domains and depressive problems. With respect to achievement-related status, this is at least partly due to the fact that there are several well-documented strategies to induce achievement-related social stress in males (e.g., defeat in aggressive encounters), but hardly any for females, among other things because it is hard to obtain strong dominance relationships in female animals (Haller, Fuchs, Halász, \& Makara, 1998). Rather than winning or losing in competitive encounters, females seem to be sensitive to situations which disturb their relationships with other animals in the group, such as social isolation (Holston, Scallet, Ali, \& Turner, 1991) and instability (Haller et al., 1998). There is some evidence for gender differences in humans as well. In a study where men and women were subjected to a series of different stress conditions, men appeared physiologically more reactive to achievement challenges, and women to social rejection challenges (Stroud, Salovey, \& Epel, 2002). Consistent with this, work problems and downward social mobility (i.e., lower achievement-related status) have been found to be associated with men's mental health in particular, while women are more sensitive to problems in getting along with dear ones and peer rejection (e.g., Brendgen, Wanner, Morin, \& Vitaro, 2005; Kendler, Thornton, \& Prescott, 2001; 
Tiffin, Pearce, \& Parker, 2005). Taken together, these results suggest gender differences in the salience of specific domains of social status. We propose that autonomy and dominance are more important sources of well-being for males than for females, so that boys will be especially sensitive to achievement-related life events and status loss (Price et al., 1994; Rose \& Rudolph, 2006). Girls' depressive problems, on the other hand, are expected to be more strongly associated to affection-related peer nominations. Compared to boys, adolescent girls exhibit greater affiliative needs, increasing their sensitivity to conflict and rejection within interpersonal relationships (Cyranowski, Frank, Young, \& Shear, 2000; Prinstein \& Aikins, 2004).

\section{Present study}

We have studied the relationship between early adolescents' depressive problems and social status in peers comprising an everyday social network. We chose to study classroom social status as measured by peer nominations, as this is a social environment in which adolescents spend a large part of the day, and are engaged in comparable activities. The fact that school attendance is compulsory in early adolescence, hence the situation is inescapable, is also relevant in this respect, because entrapment has been found to be a particularly potent elicitor of depressive(-like) emotions and behaviors (Brown et al., 1995; Gilbert \& Allan, 1998). Peer status was assessed by sociometric nominations, which are generally considered the most reliable and valid indices of peer status (Coie \& Dodge, 1983). Because the association between depression and peer status might be confounded by comorbid conduct problems (Connell \& Dishion, 2006; Kiesner, 2002), we adjusted for comorbidity in our analyses.

We hypothesized that low peer status in the achievementrelated domain would be most relevant for depressive problems in boys, whereas girls' depressive problems would be more strongly associated with low affection-related peer status. A further hypothesis was that high peer status in a particular area, although not necessarily associated with the probability of depressive problems in itself, would reduce the association between depressive problems and low status in another status area.

\section{Method}

Sample

The TRacking Adolescents' Individual Lives Survey (TRAILS) is a prospective cohort study of Dutch (pre)adolescents, with the aim to chart and explain the development of mental health from preadolescence into adulthood, which started in 2001.
Sample selection involved two steps. First, five municipalities in the North of the Netherlands, including both urban and rural areas, were requested to give names and addresses of all inhabitants born between 10-01-1989 and 09-30-1990 (first two municipalities) or 10-01-1990 and 09-30-1991 (last three municipalities), yielding 3483 names. Simultaneously, primary schools (including schools for special education) within these municipalities were approached with the request to participate in TRAILS. School participation was a prerequisite for eligible children and their parents to be approached by the TRAILS staff. Of the 135 primary schools within the municipalities, 122 (90.4\% of the schools accommodating $90.3 \%$ of the children) agreed to participate in the study.

If schools agreed to participate, parents (or guardians) and children received brochures with information about the study; and a TRAILS staff member visited the school to inform eligible children about the study. Shortly thereafter a TRAILS interviewer contacted parents by telephone to ask whether they and their child were willing to participate in the study. Respondents with an unlisted telephone number were requested by mail to pass on their number. If they reacted neither to that letter, nor to a reminder letter sent a few weeks later, staff members paid personal visits to their house. Parents who refused to participate were asked for permission to call back in about 2 months. If both parents and children agreed to participate, parental written informed consent was obtained after the procedures had been fully explained. Children were excluded from the study if they were incapable of participating due to mental retardation or a serious physical illness or handicap, or if no Dutch-speaking parent or parent surrogate was available and it was not feasible to administer any of the measurements in the parent's language. Of all children approached for enrollment in the study $(N=3145)$, $6.7 \%$ were excluded because of mental or physical incapability or language problems. Of the remaining 2935 children, $76.0 \%(N=2230$, mean age $=11.09, S D=0.56,50.8 \%$ girls) were enrolled in the study (i.e., both child and parent agreed to participate). Responders and non-responders did not differ with respect to the prevalence of teacher-rated problem behavior, nor regarding associations between sociodemographic variables and mental health outcomes (De Winter et al., 2005).

The present study is based on data from the second assessment wave of TRAILS (T2), which was held 2 to 3 years after baseline assessment (mean number of months 29.44, $S D=5.37$, range 16.69-48.06). During this wave, questionnaires were filled out by the adolescents, their parents, and their teachers. The adolescents filled out their questionnaires at school, in the classroom, under the supervision of one or more TRAILS assistants. In addition to the regular questionnaires, which were filled out by TRAILS participants only, the T2 assessment wave also included peer nominations, 
which were collected in both TRAILS participants and their classmates, at a separate occasion. Of the 2230 baseline participants, $96.4 \%$ ( $N=2149,51.0 \%$ girls $)$ participated in the first follow-up assessment (T2). Mean age at T2 was 13.56, $S D=0.53$.

\section{Subsample with peer information}

Peer nominations were assessed in classes with at least three regular TRAILS participants. In total, 150 school classes within 34 schools met this criterion and agreed to participate. Two schools dropped out because of planning difficulties, while one school did not give permission to assess peer nominations within the class. At this school, we collected nominations from TRAILS participants only, providing there were more than 10 participants per class. Schools provided the names of classmates of TRAILS participants. Subsequently, all eligible students received an information letter for themselves as well as their parents in which they were asked to participate in this part of the data collection. If students or their parents refrained from participation they were requested to send a reply card within 10 days. Passive informed consent was adequate for non-TRAILS participants because they were used as informants rather than being study subjects themselves. A total number of 98 students, 3 of whom were regular TRAILS participants, refused to participate. Peer nominations were assessed approximately 2 weeks after the information letter had been sent. The assessment of the peer nominations lasted about $15 \mathrm{~min}$ and took place during the regular lessons. Two participating classes were excluded due to too many recent changes in the composition of the class. In total, 3334 students, 1012 of whom were regular TRAILS participants, filled out the questionnaire and nominated their classmates (outdegree), whereas 3798 students, 1078 of whom TRAILS respondents, were nominated by others (indegree). These 1078 adolescents did not differ from the rest of the TRAILS participants regarding gender, $\chi^{2}(1, N=2149)=1.17, p=.28$, or depressive problems, $t(2125)=-1.15, p=.25$, but were slightly younger (mean age 13.52, $S D=0.51$, versus $13.60, S D=0.54$ ), $t(2085)=3.49, p<.001$. Persons with missing or unreliable data on depressive problems were excluded, leaving 1046 cases for analysis.

\section{Measures}

\section{Affection- and achievement related status}

Respondents could nominate any of their classmates on a total of 18 questions, covering a wide range of issues and behaviors (e.g., gossiping, helping others, substance abuse). For the purpose of this study, we selected six questions, three of which referred to affection-related status (Which classmates do you like? Which classmates do you totally dislike? Which classmates are your best friends?), and three to achievement-related status (Who are good at sports? Who are good learners? Who are good-looking?). For each of these questions, we used the proportion of nominations (indegree) as a measure of peer status. Despite the fact that being goodlooking is usually more due to inherited features than to personal accomplishments, it was classified as achievementrelated, because it is a salient social-ranking dimension in adolescence, which has been found to contribute to a higher social ranking and influence through halo effects (beautiful is good) (Anderson et al., 2001; Eagly, Ashmore, Makhijani, \& Longo, 1991; Feingold, 1992).

\section{Depressive problems}

Internalizing and externalizing problem behaviors were assessed by the Child Behavior Checklist (CBCL), one of the most commonly used questionnaires in current child and adolescent psychiatric research (Achenbach, 1991a; Verhulst \& Achenbach, 1995). It contains a list of 120 behavioral and emotional problems, which parents can rate as $0=$ not true, $1=$ somewhat or sometimes true, or $2=$ very or often true in the past 6 months. In addition to the CBCL, we administered the self-report version of this questionnaire, the Youth Self-Report (YSR, Achenbach, 1991b). The original, empirically derived, CBCL and YSR scales did not distinguish between anxiety and depressive problems. In order to improve the correspondence with clinical diagnostic categories, Achenbach, Dumenci, and Rescorla (2003) constructed DSM-IV scales for CBCL/YSR problem behaviors, based on international experts' ratings. The resulting CBCL/YSR Depressive Problems scale consists of 13 items (Cronbach's $\alpha$ CBCL $=0.73$, YSR $=0.77$ ) covering depressed mood, anhedonia, loss of energy, feelings of worthlessness and guilt, suicidal ideation, sleep problems, and eating problems. The scale has been found to correspond more closely to DSM-IV Major Depressive Disorder than the original CBCL/YSR scales (Van Lang, Ferdinand, Oldehinkel, Ormel, \& Verhulst, 2005). Test-retest reliabilities of the DSM-IV scales are good, CBCL: $r=0.88$; YSR: $r=0.79$ (Achenbach et al., 2003). The mean item score of the CBCL-scale was $0.15(S D=0.19$, range $0-1.15)$ and the mean item score of the YSR-scale 0.27 ( $S D=0.26$, range $0-1.72$ ), while $6.1 \%$ (CBCL) and $16.9 \%$ (YSR) of the scores were greater than 0.5 (which implies that more than half of the symptoms were rated as at least somewhat true and/or more than $25 \%$ of the symptoms as very true).

The agreement between parent-reported and adolescentreported depressive problems was moderate, $r=.41$. Because depressive problems rated as present by both parent and adolescent are assumed to be more severe (more generalized) than problems rated by only one informant, we used 
the mean of the standardized parent and adolescent scores as a measure of depressive symptoms in this study. When data of one informant were missing or unreliable (YSRs: $n=10$, CBCLs: $n=81$ ), the composite score was based on only one informant.

\section{Disruptive behavior}

Disruptive behavior was included to adjust for comorbidity. Disruptive behavior was assessed with the CBCL and the YSR, by combining the items for Oppositional Defiant Disorder and Conduct Disorder, which resulted in a scale of 22 (CBCL, Cronbach's $\alpha=0.86$ ) or 20 (YSR, Cronbach's $\alpha=0.79)$ items.

\section{Statistical analysis}

First, means of and correlations between the variables used in the study were calculated and gender differences tested by means of, respectively, $t$-tests and $z$-tests.

Subsequently, depressive problems were predicted by peer-status variables in a linear regression model. Standard errors were adjusted for possibly dependent observations within classes, using the cluster option available in the statistical package of STATA (StataCorp., 2003). We adjusted for disruptive behavior by including it as an independent variable in all regression analyses. Continuous variables were standardized to mean 0 and standard deviation 1 to ease interpretation of the regression coefficients. In order to be able to distinguish between associations with low status and associations with high status, each of the peer-status variables were categorized into low status (below the 20th percentile), high status (above the 80th percentile), and intermediate status (between the 20th and 80th percentile). For being disliked, high status referred to the lowest $20 \%$ (few nominations) and low status to the highest $20 \%$ (many nominations). Status was included in the analyses as dummy variables, with intermediate status as the reference category. We analyzed both the effects of each status area individually, and the effects of all areas adjusted for each other. The analyses were stratified by gender. To establish if gender differences were statistically significant, we performed a two-step regression analysis in the total sample. In the first step, main effects of all peer-status variables were entered in the model, as well as gender and disruptive problems. Interactions between gender and each of the peer-status variables, if any, were entered in a second step, by forward stepwise selection with a criterion for entry of $p<.10$.

Finally, we examined whether low status in (at least) one area could be compensated by high status in one or more other areas. Peer-status variables that were significantly related to depressive problems (as established by correlations with the effects of gender and disruptive behavior partialled out) were used to create four combined status groups: $1=$ low $\&$ high, referring to adolescents with a low status (i.e., below the 20th percentile) in at least one area and a high status (above the 80th percentile) in at least one area; $2=$ only low, designating adolescents with a low status in at least one area and no high status; $3=$ only high, representing adolescents with a high status in at least one area and no low status, and $4=$ intermediate, that is, adolescents with an intermediate status in all areas. Depressive problems in the only-low, only-high, and intermediate group were compared to those in the low \& high group (the reference category) by linear regression analysis, adjusting for disruptive behaviors and for dependent observations within classes. Gender differences in each of the associations were tested by interaction effects. A lower depression score in the low \& high group than in the only-low group suggests that compensation of a low status by a high status in another area is possible; a lower depression score in the only-high group than in the low \& high group suggests that a low status counteracts the benefits of a high status in another area. Comparison of the intermediate group with the low \& high group provides insight in the differences between being extraordinary (in any direction) and being average. To take into account that the specific areas may represent the two broad domains of achievementrelated and affection-related status disproportionately, this procedure was repeated for the strongest predictor of each.

For all analyses, a $p$-value smaller than .05 was considered statistically significant. Because we performed multiple statistical tests, the results may suffer from capitalization on chance: one would expect some $5 \%$ of the associations examined to be significant merely on the basis of chance, and the probability to find at least one significant effect increases with every additional statistical test. We therefore recommend to consider the general pattern of associations, rather than interpreting each individual effect as if it were the only one tested.

\section{Results}

\section{Descriptive statistics}

Table 1 presents descriptive statistics of the variables used in this study. Girls had more nominations for being good learners and good-looking, while boys were nominated more often as being good at sports. Affection-related status domains showed no significant gender differences. Girls had more depressive problems, and boys more disruptive behavior problems.

\section{Bivariate associations}

Correlations between the peer nominations were generally moderate to high (Table 2). Being a good learner was not 
Table 1 Mean (standard deviation) of peer status and mental health, by gender

\begin{tabular}{|c|c|c|c|c|}
\hline & \multicolumn{2}{|l|}{ Mean $(S D)$} & \multirow[b]{2}{*}{ Difference t-test ${ }^{b}$} & \multirow[b]{2}{*}{ Effect size $^{c}$} \\
\hline & Girls $(N=549)$ & Boys $(N=497)$ & & \\
\hline \multicolumn{5}{|c|}{ Proportion nominations for being } \\
\hline Liked & $0.56(0.21)$ & $0.55(0.20)$ & $t=-0.26, p=.80$ & 0.05 \\
\hline Disliked & $0.10(0.13)$ & $0.12(0.15)$ & $t=1.61, p=.11$ & -0.14 \\
\hline Best friend & $0.20(0.12)$ & $0.21(0.13)$ & $t=1.05, p=.30$ & -0.04 \\
\hline Good at sports & $0.22(0.21)$ & $0.40(0.29)$ & $t=11.11, p<.001$ & -0.71 \\
\hline A good learner & $0.33(0.26)$ & $0.28(0.25)$ & $t=-2.60, p=.01$ & 0.20 \\
\hline Good-looking & $0.27(0.22)$ & $0.12(0.13)$ & $t=-13.87, p<.001$ & 0.83 \\
\hline \multicolumn{5}{|l|}{ Mental health } \\
\hline Depressive Problems $^{a}$ & $0.24(0.21)$ & $0.19(0.18)$ & $t=-3.57, p<.001$ & 0.26 \\
\hline Disruptive Behavior $^{a}$ & $0.21(0.15)$ & $0.25(0.18)$ & $t=3.26, p=.001$ & -0.24 \\
\hline
\end{tabular}

${ }^{a}$ For descriptive purposes, the means are based on mean unstandardized scores of parent and adolescent reports. The tests are based on mean standardized scores.

${ }^{b}$ Effects are adjusted for possible dependence of observations within classes.

${ }^{c}$ Cohen's $d=\left(M_{1}-M_{2}\right) / \sigma_{\text {pooled }}$, where $M_{1}$ is the mean of the first group, $M_{2}$ is the mean of the second group, and $\sigma_{\text {pooled }}$ is the square root of the mean variance of the two groups $\left(\sqrt{ }\left[\left(\sigma_{1}^{2}+\sigma_{2}^{2}\right) / 2\right]\right)$.

significantly related to being good-looking, and in girls neither to being liked and being someone's best friend. Strongest associations were found among the affection-related variables (being liked, being disliked, and being someone's best friend). In girls, depressive problems were most strongly associated with being disliked, in boys the correlation was highest for being good at sports.

\section{Hierarchy of status areas}

To distinguish between associations with low and high status, each of the peer-status variables was categorized into low status (below the 20th percentile), high status (above the 80th percentile), and intermediate status (between the 20th and 80th percentile). For being disliked, high status referred to the lowest $20 \%$ (few nominations) and low status to the highest $20 \%$ (many nominations). The distribution of the peer nominations precluded that the high-status group of being disliked contained approximately $20 \%$ of the cases: $32.0 \%$ of the adolescents were nominated by no one and hence classified as having high disliked status.

Table 3 shows gender-specific regression coefficients for each of the low- and high-status groups, vis-à-vis the intermediate group, both without and with adjustment for the other peer-status dimensions. All effects were adjusted for disruptive behavior. Together, the peer-status variables explained $6.4 \%$ of the variance in boys, and $7.7 \%$ in girls.

It is interesting to note that in girls, only low status appeared associated with depressive problems, while in boys, high status tended to be relevant as well, especially in the affection domain. Both without and with adjustment for other status areas, girls' regression coefficients were highest for a low status in being liked, and boys' coefficients for a low status in sports, indicating that girls and boys with few nominations regarding these areas had the highest number of estimated depressive problems. When all status areas were

Table 2 Correlations between peer status and mental health, in girls (above the diagonal) and boys (below the diagonal)

\begin{tabular}{|c|c|c|c|c|c|c|c|c|}
\hline & Liked & Disliked & Best friend & Good at sports & Good learner & Good-looking & $\begin{array}{l}\text { Depressive } \\
\text { problems }\end{array}$ & $\begin{array}{l}\text { Disruptive } \\
\text { behavior }\end{array}$ \\
\hline Liked & & -.62 & .49 & .34 & .06 & .55 & -.17 & -.07 \\
\hline Disliked & -.68 & & -.34 & -.23 & -.18 & -.36 & .21 & .14 \\
\hline Best Friend & .49 & -.36 & & .34 & .08 & .46 & -.06 & .11 \\
\hline Good at sports & .38 & -.25 & .34 & & .21 & .44 & -.15 & -.04 \\
\hline A good learner & .14 & -.16 & .15 & .15 & & .07 & -.14 & -.21 \\
\hline Good-looking & .42 & -.28 & .30 & .51 & .09 & & -.10 & .01 \\
\hline Depressive Problems ${ }^{a}$ & -.16 & .16 & -.11 & -.19 & -.09 & -.12 & & .52 \\
\hline Disruptive Behavior $^{a}$ & -.09 & .20 & -.02 & .03 & -.20 & -.04 & .48 & \\
\hline
\end{tabular}

Note. Bold: $p<.05$, italics: significant gender difference.

${ }^{a}$ Standardized scores, based on mean standardized scores of parent and adolescent reports. 
Table 3 Prediction of depressive problems by low and high peer-status in several areas, adjusted for disruptive behavior, stratified by gender

Note. Effects of low and high status are with regard to intermediate status. Depressive problems were standardized to mean 0 and standard deviation 1 . Effects are adjusted for possible dependence of observations within classes.

${ }^{a}$ As opposed to other status areas, a low status at being disliked reflects many nominations, and a high status few.

Bold: $p<.05$.

\begin{tabular}{|c|c|c|c|c|c|}
\hline \multirow[b]{3}{*}{ Status area } & \multirow[b]{3}{*}{ Status } & \multicolumn{4}{|l|}{$B(p)$} \\
\hline & & \multicolumn{2}{|c|}{ Unadjusted for other areas } & \multicolumn{2}{|c|}{ Adjusted for other areas } \\
\hline & & Girls & Boys & Girls & Boys \\
\hline \multicolumn{6}{|l|}{ Affection } \\
\hline \multirow[t]{2}{*}{ Liked } & Low & $0.41(<.001)$ & $0.16(.05)$ & $0.33(.02)$ & $0.02(.85)$ \\
\hline & High & $-0.07(.48)$ & $-0.21(.008)$ & $-0.03(.80)$ & $-0.10(.28)$ \\
\hline \multirow[t]{2}{*}{ Disliked } & Low $^{a}$ & $0.21(.08)$ & $0.00(.95)$ & $0.05(.72)$ & $-0.11(.33)$ \\
\hline & $\operatorname{High}^{a}$ & $-0.13(.11)$ & $-0.22(.002)$ & $-0.06(.47)$ & $-0.14(.05)$ \\
\hline \multirow[t]{2}{*}{ Best friend } & Low & $0.24(.02)$ & $0.22(.02)$ & $0.08(.47)$ & $0.13(.19)$ \\
\hline & High & $-0.14(.15)$ & $-0.15(.046)$ & $-0.07(.47)$ & $-0.05(.49)$ \\
\hline \multicolumn{6}{|l|}{ Achievement } \\
\hline \multirow[t]{2}{*}{ Good at sports } & Low & $0.27(.004)$ & $0.44(<.001)$ & $0.19(.08)$ & $0.38(.005)$ \\
\hline & High & $-0.12(.34)$ & $-0.17(.02)$ & $-0.07(.57)$ & $-0.10(.17)$ \\
\hline \multirow[t]{2}{*}{ Good learner } & Low & $0.12(.35)$ & $0.08(.39)$ & $0.05(.68)$ & $0.02(.79)$ \\
\hline & High & $-0.02(.83)$ & $-0.01(.91)$ & $0.01(.88)$ & $0.04(.68)$ \\
\hline \multirow[t]{2}{*}{ Good-looking } & Low & $0.12(.40)$ & $0.17(.04)$ & $-0.10(.52)$ & $0.01(.92)$ \\
\hline & High & $-0.11(.13)$ & $-0.13(.19)$ & $0.06(.45)$ & $-0.04(.67)$ \\
\hline
\end{tabular}

analyzed jointly, these two associations were the only significant ones. Without adjustment for disruptive problems, the effects remained largely the same, except that the effect of a high status for being disliked (reflecting no nominations) became significant in boys, $B=-0.20, p=.02 .{ }^{1}$

Gender differences in the associations between peer status and depressive problems were tested by interaction effects of gender and each of the peer-status variables in the total sample, using a forward stepwise selection procedure (with criterion for entry $p<.10$ ) after all main effects had been entered in the model. Gender interactions with a low status on being liked, $B=0.32, p=.04$, and a low status on being good at sports, $B=-0.26, p=.09$, were both selected by this procedure, but the latter only showed a trend and did not reach the significance criterion of $p<.05$. Other status variables did not the meet the entry criterion.

\section{Across-area compensation}

With the effects of gender and disruptive behavior partialled out, all peer-status variables were significantly associated with depressive problems, except being a good learner, $r=-0.02, p=.60$. This variable was excluded from further analyses, hence the index describing the combined sta-

\footnotetext{
${ }^{1} \mathrm{CBCL} / \mathrm{YSR}$ depressive problems were assessed at the first assessment wave (T1, at approximately age 11) as well. Adjustment for T1 depressive problems yielded largely comparable results, that is, a low status in being liked (few nominations) had the largest regression coefficient in girls $(B=0.31, p=.002$; adjusted for other status domains $B=0.30$, $p=.006$ ), and a low status in sports (few nominations for being a good sportsperson) had the largest coefficient in boys ( $B=0.23, p=.02)$, though the effect just failed to reach statistical significance when adjusted for the other status domains $(B=0.20, p=.06)$. Full data are available upon request.
}

tuses was based on five areas. Of the total sample, $17.5 \%$ fell in the low \& high group, $32.0 \%$ in the only-low group, $40.8 \%$ in the only-high group, and $9.7 \%$ in the intermediate group. This distribution was approximately equal for girls and boys, $\chi^{2}(3, N=1046)=2.23, p=.53$. The regression coefficients for the only-low, only-high and intermediate group, in relation to the high \& low group, are presented in Table 4.

The coefficients indicate that the only-low group had more depressive problems than the low \& high group, while the only-high and intermediate group did not differ significantly from the low \& high group. Thus, these results suggest that the risk associated with low status in one area can be compensated by a high status in another area, while the opposite (i.e., counteraction of the beneficial effects of a high status by a low status in another area) is not true, at least not to the same degree. None of the associations showed gender differences (all $p$-values $>.42$ ).

To test the robustness of these findings, we also constructed a combined status index (with the categories only low, only high, low \& high, and intermediate as defined in

Table 4 Prediction of depressive problems by cross-area peer status groups, adjusted for disruptive behavior

\begin{tabular}{llr}
\hline Status group & $n$ & $B(p)$ \\
\hline Low \& high (reference category) & 183 & \multicolumn{1}{l}{-} \\
Only low & 335 & $\mathbf{0 . 3 0}(\mathbf{. 0 0 1})$ \\
Only high & 427 & $-0.11(0.12)$ \\
Intermediate & 101 & $0.02(0.87)$ \\
\hline
\end{tabular}

Note. Low \& High: low status in at least one area and high status in at least one area; Only Low: low status in at least one area and no high status; Only High: high status in at least one area and no low status, Intermediate: intermediate status in all areas. Effects are adjusted for possible dependence of observations within classes.

Bold: $p<.05$. 
the method section) based on only the strongest predictors from each of the two broad domains of achievement-related and affection-related status, that is, being liked and being good at sports respectively. The use of this alternative status measure yielded similar results: more depressive problems in the only-low group than in the low $\&$ high group, $B=0.33$, $p=.004$; no significant differences between the low \& high group and, respectively, the only-high group, $B=-0.10$, $p=.33$, and the intermediate group, $B=0.07, p=.55$; and no gender differences (all $p$-values $>.31$ ).

\section{Discussion}

Striving for status has been proposed as a universal human motive, and a wealth of evidence has indicated that persons' status within their group influences their psychological and physiological well-being (e.g., Anderson et al., 2001). For adolescents, one of the most salient social groups is made up by their classmates. In this study on associations between classroom peer status and depressive problems in young adolescents from the general population, the peer status variables explained about $7 \%$ of the variance in depressive problems (unadjusted for measurement error, hence underestimating the true variance), which is a modest, yet noteworthy amount.

We hypothesized that peer status in the achievementrelated domain would be most relevant for depressive problems in boys, whereas girls' depressive problems would be more strongly associated to their affection-related peer nominations. A further hypothesis was that high alternative hierarchical positions would (wholly or partly) counteract the association between depressive problems and low status in a particular status area. These hypotheses were largely supported by the data, although it should be noted that the expected patterns were not found in all status areas investigated. Compared with other status areas, not being good at sports, hence a low achievement-related status, was most strongly associated with depressive problems in boys; while not being liked, hence a low status on an affection-related area, had the strongest association with depressive problems in girls. However, our data suggest that not being good at sports may affect girls' well-being as well, and the gender difference regarding this status domain, although showing a trend, was not statistically significant. Not being liked, on the other hand, appeared to be related to depressive problems in girls only. Hence, girls seem to be more sensitive than boys to affection-related status, particularly to a lack of peers that like them.

Low status versus high status

In general, the risk associated with a low group status was stronger than the resilience associated with a high status, especially in girls, and when the effects of all status areas were adjusted for each other, the only variables that remained significantly associated with depressive problems reflected a low status. Low peer status may lead to depressive problems through a variety of pathways, such as a reduced opportunity to make friends, controlling or dominating behavior by others, and expressions of disapproval or contempt (DeaterDeckard, 2001). All of these may undermine self-esteem and invoke feelings of loneliness (Asher \& Wheeler, 1985; O'Brien \& Bierman, 1988), which are known risk factors for depressive problems (e.g., Monroe \& Hadjiyannakis, 2002; Pelkonen, Marttunen, \& Aro, 2003).

Although a high peer status does not seem to be very effective in preventing depressive problems in itself, this may be different for those with a low status in another area: a high status appeared to have the potential to compensate the risk associated with a low status. Adolescents with a low status in at least one area and no high status to counterbalance this had most depressive problems, which supports the idea that depression is particularly likely when no escape from the degrading situation seems possible (Brown et al., 1995), and underscores once more the importance of emphasizing and stimulating adolescents' strengths and talents, particularly for adolescents with weaknesses in other areas.

\section{Gender differences}

The gender differences found in this study, notably the fact that a direct association between affection-related status and depressive problems was found only in girls, add evidence to the notion that interpersonal stressors are more depressogenic for adolescent girls than for boys (e.g., Brendgen et al., 2005; Shih, Eberhart, Hammen, \& Brennan, 2006). Associations with depressive problems were adjusted for disruptive behaviors to take into account comorbidity of the two. Without adjustment for disruptive behaviors, being disliked was significantly related to boys' depressive problems, which may indicate that disliked boys tend to show disruptive behavior rather than (solely) depressive problems. Achievement-related status was most strongly related to depressive problems in boys. Compared to girls, boys focus more on agentic goals, including their own dominance on the peer group (e.g., Rose \& Rudolph, 2006), which apparently makes them more vulnerable to low status in relevant areas. However, we found some indications that sports-related achievements may be relevant for girls too. This finding could hint at a dwindling of traditional socio-cultural gender differences; but it could as well be due to the fact that not being good at sports reflects not only a low probability of winning in ritual fights, but also lack of physical energy and activity, which is likely to occur in both depressed boys and depressed girls. The issue of reverse causality is discussed more extensively hereafter. 
Differences between specific status areas

Within the achievement-related domain, sporting performance was more strongly associated with depressive problems than being a good learner and being good-looking. Sports, more than theoretical subjects and outward appearances, reflect ritual agonistic behavior, with the end being signified by the loser yielding and signals of superiority by the winner (Rohde, 2001). In other words, sports are much more closely related to social defeat than the other two achievement domains. But other factors may account for the relatively exceptional position of sports as well. To start with, adolescents who are good at sports may do relatively more physical exercise, which can help to reduce depressive problems (e.g., Nabkasorn et al., 2006), so there may be a direct effect of sports on mental health, on top of the effect through peer status. Furthermore, being good at sports increases the likelihood of team membership, which in turn may result into admiration and new friendships. The latter could be especially relevant for boys, who tend to have multiple activity-related friendships rather than a few close friends (e.g., Moller, Hymel, \& Rubin, 1992). The association between being a good learner and having a high peer status is probably more equivocal than that between being good at sports and peer popularity. Although some studies found positive correlations between grade point average and popularity among peers (e.g., Cauce, 1987; Green, Forehand, Beck, \& Vosk, 1980), others suggested that intelligence is not associated with peer status (Luthar \& McMahon, 1996), and that overachievers do not have a secure position in their peer group (Hartup, 1970). In fact, Bukowski, Sippola, and Newcomb (2000) showed that good classroom behavior starts to loose its attraction for peers during early adolescence, in favor of more aggressive behaviors. As concerning the role of being considered good-looking, our results seem to contradict earlier findings that physically unattractive adolescents are likely to receive more negative feedback (Burns \& Farina, 1992; Cash, 1995), and that body dissatisfaction is an independent risk factor for (girls') depressive problems in adolescence (e.g., Stice, Hayward, Cameron, Killen, \& Taylor, 2000). That peer nominations for being good-looking did not independently contribute to adolescents' (lack of) depressive problems in our study could be due to the fact that peer judgments have little to do with one's own body image (Rosenblum \& Lewis, 1999). Furthermore, not being goodlooking is not necessarily equivalent to being ugly; in other words, the question 'Who is unattractive?' might have been a stronger correlate of depressive problems than the question 'Who is good-looking?.'

Within the affection-related domain, which appeared to be relevant to girls in particular, not being liked was the most salient factor in relation to depressive problems. In other words, it does not seem to matter much whether or not some people dislike you, as long as there are still others that like you. A lack of sympathizers is a threat to mental health. From an evolutionary point of view, this makes good sense, because being liked by others can offer social support and protection against being expelled from the group, and the 'need to belong' is a fundamental motivation (Baumeister \& Leary, 1995; Fiske, 2004).

Limitations, strengths, and recommendations for future research

Our study has some limitations. To start with, the CBCL/YSR Depressive Problems scale was not developed to assess depressive problems according to DSM-IV criteria, but constructed on the basis of expert ratings of the original, empirically derived, CBCL and YSR scale items. Consequently, the items do not represent one-to-one counterparts of all DSM-IV criteria, and inferences about associations between peer status and DSM-IV Major Depression are putative. Furthermore, we performed multiple statistical tests, which increases the probability of chance findings and warrants replications in other samples. A final limitation of the study is the cross-sectional and non-experimental nature of our data, which does not allow causal interpretation of the associations found (Kraemer et al., 1997). Most likely, however, the association between peer status and depressive problems is bidirectional: not only does low peer status induce depressive problems, depressed children and adolescents tend to display maladaptive interpersonal behavior as well (e.g., Altman \& Gotlib, 1988; Baker, Milich, \& Manolis, 1996). A bidirectional association is especially plausible with respect to sporting performance. Being looked down on because you are bad at sports may reduce self confidence and through this incite the development of depressive problems; but it is just as likely that depressive problems, which often include lack of energy and motivation, have a negative impact on adolescents' sporting achievements. Similarly, one could argue that the association between depressive problems and not being liked is a two-way one. Having no allies in a peer group can be devastating for your self-worth and hence trigger depression, but depressed behavior may also fend off others (e.g., Prinstein, Borelli, Cheah, Simon, \& Aikins, 2005). It seems plausible, however, that if depression were a cause of not being liked, we would expect that to happen in both boys and girls and not in girls only. We thus assume that not being liked is actually a risk factor for depression, at least in girls.

Compared to the vast literature on peer processes predicting conduct problems, research on peer processes in depression has been relatively rare (Connell \& Dishion, 2006; Deater-Deckard, 2001). To the best of our knowledge, our study is one of the first to examine the association between status-related peer nominations and depressive problems in a large population cohort of early adolescents. In addition 
to the size and representativeness of our sample, important assets of this study relate to the use of multiple informants, multiple aspects of peer status, and multiple outcomes, which allowed adjusting for comorbid disruptive behavior. Hence, we feel that it is an excellent starting point for further research. We propose three lines of extension. Firstly, the cross-sectional associations should be extended to (bidirectional) patterns of associations across time, to be better able to distinguish between concomitants and risk factors (Kraemer et al., 1997). Secondly, the study could be extended to include other outcomes, not only within the domain of psychopathology, but also regarding somatic health. Thirdly, it is highly relevant from a public-health point of view to (further) explore to what extent and how peer processes can be manipulated in order to prevent aversive outcomes.

Acknowledgments This research is part of the TRacking Adolescents' Individual Lives Survey (TRAILS). Participating centers of TRAILS include various Departments of the University of Groningen, the Erasmus Medical Center of Rotterdam, the University of Nijmegen, the Trimbos Institute, and the University of Utrecht, The Netherlands. TRAILS is financially supported by grants from the Netherlands Organization for Scientific Research (GB-MW 940-38-011, GB-MAG 480-01-006, ZonMw 100.001.001; NWO 175.010.2003.005) and the Department of Justice (WODC), and by the participating centers.

\section{References}

Achenbach, T. M. (1991a). Manual for the Child Behavior Checklist/ 4-18 and 1991 profile. Burlington VT: University of Vermont.

Achenbach, T. M. (1991b). Manual for the Youth Self-Report and 1991 profile. Burlington VT: University of Vermont.

Achenbach, T. M., Dumenci, L., \& Rescorla, L. A. (2003). DSMoriented and empirically based approaches to constructing scales from the same items pools. Journal of Clinical Child and Adolescent Psychology, 32, 328-340.

Altman, E., \& Gotlib, I. (1988). The social behavior of depressed children: an observational study. Journal of Abnormal Child Psychology, 25, 29-44.

Anderson, C., John, O. P., Keltner, D., \& Kring, A. M. (2001). Who attains social status? Effects of personality and physical attractiveness in social groups. Journal of Personality and Social Psychology, 81, 116-132.

Asher, S. R., \& Wheeler, V. A. (1985). Children's loneliness: a comparison of rejected and neglected peer status. Journal of Consulting and Clinical Psychology, 53, 500-505.

Baker, M., Milich, R., \& Manolis, M. (1996). Peer interactions of dysphoric adolescents. Journal of Abnormal Child Psychology, 24, 241-255

Baumeister, R. F., \& Leary, M. R. (1995) The need to belong: Desire for interpersonal attachments as a fundamental human motivation. Psychological Bulletin, 117, 497-529.

Blanchard, D. C., \& Blanchard R. J. (1990). Behavioral correlates of chronic dominance-subordination relationships of male rats in a seminatural situation. Neuroscience and Biobehavioral Reviews, $14,455-462$.

Boivin, M., Poulin, F., \& Vitaro, F. (1994). Depressed mood and peer rejection in childhood. Development and Psychopathology, 6, 483498.
Brendgen, M., Wanner, B., Morin, A. J. S., \& Vitaro, F. (2005). Relations with parents and with peers, temperament, and trajectories of depressed mood during early adolescence. Journal of Abnormal Child Psychology, 33, 579-594.

Brown, G. W., Harris, T. O., \& Hepworth, C. (1995). Loss, humiliation, and entrapment among women developing depression: a patient and non-patient comparison. Psychological Medicine, 25, 813831.

Bukowski, W. M., Sippola, L. K., \& Newcomb, A. F. (2000). Variations in patterns of attraction to same- and other-sex peers during early adolescence. Developmental Psychology, 36, 147-154.

Burns, G. L., \& Farina, A. (1992). The role of physical attractiveness in adjustment. Genetic, Social and General Psychology Monographs, 118, 159-194.

Cash, T. F. (1995). Developmental teasing about physical appearance: retrospective descriptions and relationships with body image. Social Behaviour and Personality, 23, 123-129.

Cauce, A. M. (1987). School and peer competence in early adolescence. A test of domain specific self-perceived competence. Developmental Psychology, 23, 287-291.

Coie, J. D. (1990). Toward a theory of peer rejection. In S. R. Asher \& J. D. Coie (Eds.), Peer rejection in childhood (pp. 365-401). New York: Cambridge University Press.

Coie, J. D., \& Dodge, K. A. (1983). Continuities and changes in children's social status: a five-year longitudinal study. Merrill-Palmer Quarterly, 29, 261-282.

Connell A. M., \& Dishion, T. J. (2006). The contribution of peers to monthly variation in adolescent depressed mood: A short-term longitudinal study with time-varying predictors. Development and Psychopathology, 18, 139-154.

Cyranowski, J. M., Frank, E., Young, E., \& Shear, K. (2000). Adolescent onset of gender differences in lifetime rates of major depression. A theoretical model. Archives of General Psychiatry, 57, 2127.

Deater-Deckard, K. (2001). Annotation: Recent research examining the role of peer relationships in the development of psychopathology. Journal of Child Psychology and Psychiatry, 42, 565-579.

De Winter, A. F., Oldehinkel, A. J., Veenstra, R., Brunnekreef, J. A., Verhulst, F. C., \& Ormel, J. (2005). Nonresponse bias in mental health determinants and outcomes in a large sample of preadolescents. European Journal of Epidemiology, 20, 173-181.

Eagly, A. H., Ashmore, R. D., Makhijani, M. G., \& Longo, L. C. (1991). What is beautiful is good, but ...: A meta-analytic review of research on the physical attractiveness stereotype. Psychological Bulletin, 110, 109-128.

Eaton, W. W., \& Harrison, G. (2000). Epidemiology, social deprivation and community psychiatry. Current Opinion in Psychiatry, 13, $185-187$.

Feingold, A. (1992). Good-looking people are not what we think. Psychological Bulletin, 111, 304-341.

Fiske, S. T. (2004). Social beings: A core motives approach to social psychology. New York: Wiley.

Gilbert, P. (1989). Human nature and suffering. London: Lawrence Erlbaum.

Gilbert, P., \& Allan, A. (1998). The role of defeat and entrapment (arrested flight) in depression: an exploration of an evolutionary view. Psychological Medicine, 28, 585-598.

Gilbert, P., Allan, S., \& Trent, D. (1995). Involuntary subordination or dependency as key dimensions of depressive vulnerability. Journal of Clinical Psychology, 51, 740-752.

Green, K. D., Forehand, R., Beck, S. J., \& Vosk, B. (1980). An assessment of the relationship of children's social competence and children's academic achievement. Child Development, 51, 11491156.

Haller, J., Fuchs, E., Halász, J., \& Makara, G. B. (1998). Defeat is a major stressor in males while social instability is a stressor mainly 
in females: towards the development of a social stress model in female rats. Brain Research Bulletin, 50, 33-39.

Hankin, B. L., Abramson, L. Y., Moffitt, T. E., Silva, P. A., McGee, R., \& Angell, K.E. (1998). Development of depression from preadolescence to young adulthood: Emerging gender differences in a 10-year longitudinal study. Journal of Abnormal Psychology, 107, $128-140$.

Hartup, W. W. (1970). Peer interaction and social organization. In P. H. Mussen (Ed.), Carmichael's manual of child psychology, Vol. 2 (3rd edn., pp. 361-457). New York: Wiley.

Hecht, D. B., Inderbitzen, H. M., \& Bukowski, A. L. (1998). The relationship between peer status and depressive symptoms in children and adolescents. Journal of Abnormal Child Psychology, 26, 153160.

Holston, R. R., Scallet, A. C., Ali, S. F., \& Turner, B. B. (1991). "Isolation stress" revisited: Isolation-rearing effects on animal care methods. Physiology and Behavior, 49, 1107-1118.

Jackson, S. W. (1986). Melancholia and depression: From Hippocratic times to modern times. New Haven: Yale University Press.

Kendler, K. S., Thornton, L. M., \& Prescott, C. A. (2001). Gender differences in the rates of exposure to stressful life events and sensitivity to their depressogenic effects. American Journal of Psychiatry, 158, 587-593.

Kiesner, J. (2002). Depressive symptoms in early adolescence: their relation with classroom problem behavior and peer status. Journal of Research on Adolescence, 12, 463-478.

Kraemer, H. C., Kazdin, A. E., Offord, D. R., Kessler, R. C., Jensen, P. S., \& Kupfer, D. J. (1997). Coming to terms with the terms of risk. Archives of General Psychiatry, 54, 337-343.

Larson, R., \& Richards, M. (1991). Daily companionship in late childhood and early adolescence: Changing developmental contexts. Child Development, 62, 284-300.

Luthar, S. S., \& McMahon, T. J. (1996). Peer reputation among innercity adolescents: Structure and correlates. Journal of Research on Adolescence, 6, 581-603.

Moller, L.C., Hymel, S., \& Rubin, K.H. (1992). Sex typing in play and popularity in middle childhood. Sex Roles, 26, 331-353.

Monroe, S. M., \& Hadjiyannakis, K. (2002). The social environment and depression: focusing on severe life stress. In H. I. Gotlib \& C. L. Hammen (Eds.), Handbook of depression (pp. 314-340). New York: Guilford.

Nabkasorn, C., Miyai, N., Sootmongkol, A., Junprasert, S., Yamamoto, H., Arita, M., et al. (2006). Effects of physical exercise on depression, neuroendocrine stress hormones and physiological fitness in adolescent females with depressive symptoms. European Journal of Public Health, 16, 179-184.

Nettle, D. (2003). Intelligence and class mobility in the British population. British Journal of Psychology, 94, 551-561.

O'Brien, S. F., \& Bierman, K. L. (1988). Conceptions and perceived influence of peer groups: Interview with preadolescents and adolescents. Child Development, 59, 99-128.

Oldehinkel, A. J., Wittchen, H.-U., \& Schuster, P. (1999). Prevalence, 20-month incidence and outcome of unipolar depressive disorders in a community sample of adolescents. Psychological Medicine, 29, 655-668.

Pelkonen, M., Marttunen, M., \& Aro, H. (2003). Risk for depression: A 6-year follow-up of Finnish adolescents. Journal of Affective Disorders, 77, 41-51.
Price, J. S. (1972). Genetic and phylogenetic aspects of mood variations. International Journal of Mental Health, 1, 124-144.

Price, J., Sloman, L., Gardiner, R. Jr., Gilbert, P., \& Rohde, P. (1994). The social competition hypothesis of depression. British Journal of Psychiatry, 164, 309-315.

Prinstein M. J., \& Aikins, J. W. (2004). Cognitive moderators of the longitudinal association between peer rejection and adolescent depressive symptoms. Journal of Abnormal Child Psychology, $32,147-158$.

Prinstein, M. J., Borelli, J. L., Cheah, C. S., Simon, V. A., \& Aikins, J. W. (2005). Adolescent girls' interpersonal vulnerability to depressive symptoms: a longitudinal examination of reassurance-seeking and peer relationships. Journal of Abnormal Psychology, 114, 676688.

Rohde, P. (2001). The relevance of hierarchies, territories, defeat for depression in humans: hypotheses and clinical predictions. Journal of Affective Disorders, 65, 221-230.

Rose, A. J., \& Rudolph, K. D. (2006). A review of sex differences in peer relationship processes: Potential trade-offs for the emotional and behavioral development of girls and boys. Psychological Bulletin, $132,98-131$.

Rosenblum, G. D., \& Lewis, M. (1999). The relations between body image, physical attractiveness, and body mass in adolescence. Child Development, 70, 50-64.

Sapolsky, R. M. (1990). Adrenocorticol function, social rank and personality among wild baboons. Biological Psychiatry, 28, 862878.

Sapolsky, R. M. (2005). The influence of social hierarchy on primate health. Science, 308, 648-652.

Siegrist, J., \& Marmot, M. (2004). Health inequalities and the psychosocial environment-Two scientific challenges. Social Science and Medicine, 58, 1463-1473.

Shih, J. H., Eberhart, N. K., Hammen, C. L., \& Brennan, P. A. (2006). Differential exposure and reactivity to interpersonal stress predict sex differences in adolescent depression. Journal of Clinical Child and Adolescent Psychology, 35, 103-115.

StataCorp (2003). Stata statistical software: Release 8.0. College Station, TX: Stata Corporation.

Stice, E., Hayward, C., Cameron, R., Killen, J. D., \& Taylor, C. B. (2000). Body image and eating disturbances predict onset of depression in female adolescents: a longitudinal study. Journal of Abnormal Psychology, 109, 438-444.

Stroud, L. R., Salovey, P., \& Epel, E. S. (2002). Sex differences in stress responses: Social rejection versus achievement stress. Biological Psychiatry, 52, 318-327.

Tiffin, P. A., Pearce, M. S., \& Parker, L. (2005). Social mobility over the lifecourse and self reported mental health at age 50: Prospective cohort study. Journal of Epidemiology and Community Health, 59, 870-872.

Van Lang, N. D. J., Ferdinand, R. F., Oldehinkel, A. J., Ormel, J., \& Verhulst, F. C. (2005). Validity of the DSM-IV scales Affective Problems and Anxiety Problems of the Youth Self-Report. Behaviour Research and Therapy, 43, 1485-1494.

Verhulst, F. C., \& Achenbach, T. M. (1995). Empirically based assessment and taxonomy of psychopathology: Cross-cultural applications. European Child and Adolescent Psychiatry, 4, $61-76$. 